\title{
Factors Influencing the Adoption of Big Data Analytics in the Digital Transformation Era: Case Study of Jordanian SMEs
}

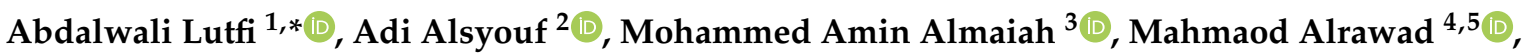 \\ Ahmed Abdullah Khalil Abdo ${ }^{6,7}{ }^{(0)}$, Akif Lutfi Al-Khasawneh ${ }^{8}$, Nahla Ibrahim ${ }^{1}$ and Mohamed Saad ${ }^{1}$
}

check for

updates

Citation: Lutfi, A.; Alsyouf, A.;

Almaiah, M.A.; Alrawad, M.; Abdo, A.A.K.; Al-Khasawneh, A.L.; Ibrahim, N.; Saad, M. Factors Influencing the Adoption of Big Data Analytics in the Digital Transformation Era: Case Study of Jordanian SMEs. Sustainability 2022, 14, 1802. https:// doi.org/10.3390/su14031802

Academic Editor: Roberto Cerchione

Received: 23 December 2021

Accepted: 25 January 2022

Published: 4 February 2022

Publisher's Note: MDPI stays neutral with regard to jurisdictional claims in published maps and institutional affiliations.

Copyright: (C) 2022 by the authors. Licensee MDPI, Basel, Switzerland. This article is an open access article distributed under the terms and conditions of the Creative Commons Attribution (CC BY) license (https:// creativecommons.org/licenses/by/ $4.0 /)$.
1 Department of Accounting, College of Business, King Faisal University, Al-Ahsa 31982, Saudi Arabia; netman@kfu.edu.sa (N.I.); msoahmad@kfu.edu.sa (M.S.)

2 Department of Managing Health Services and Hospitals, Faculty of Business Rabigh, College of Business (COB), King Abdulaziz University, P.O. Box 344, Jeddah 21991, Saudi Arabia; oal@kau.edu.sa

3 Department of Computer Networks, College of Computer Sciences and Information Technology, King Faisal University, Al-Ahsa 31982, Saudi Arabia; malmaiah@kfu.edu.sa

4 Quantitative Method Department, College of Business Administration, King Faisal University, Al-Ahsa 31982, Saudi Arabia; malrawad@kfu.edu.sa

5 College of Business Administration and Economics, Al-Hussein Bin Talal University, Ma'an 71111, Jordan

6 Accounting Department, College of Science and Human Studies, Shaqra University, P.O. Box 33, Shaqra 11961, Saudi Arabia; a.klil@su.edu.sa

7 Accounting Department, Thebes Academy in Saqqara, Saqqara 11434, Egypt

8 Financial \& Administrative Sciences Department, Al-Balqa' Applied University, P.O. Box 50, Al-Huson 21510, Jordan; khasawneha@ipa.edu.sa

* Correspondence: aalkhassawneh@kfu.edu.sa

\begin{abstract}
Big data (BD) analytics has been increasingly gaining attraction in both practice and theory in light of its opportunities, barriers and expected benefits. In particular, emerging economics view big data analytics as having great importance despite the fact that it has been in a constant struggle with the barriers that prevent its adoption. Thus, this study primarily attempted to determine the drivers of big data analytics in the context of a developing economy, Jordan. The study examined the influence of technological, organizational and environmental factors on big data adoption in the Jordanian SMEs context, using PLS-SEM for the analysis. The empirical results revealed that the relative advantage, complexity, security, top management support, organizational readiness and government support influence the adoption of BD, whilst pressure of competition and compatibility appeared to be of insignificant influence. The findings are expected to contribute to enterprise management and strategic use of data analytics in the present dynamic market environment, for both researcher and practitioner circles concerned with the adoption of big data in developing countries.
\end{abstract}

Keywords: big data analytics (BDA); big data (BD); big data adoption; security; TOE framework; SMEs; Jordan

\section{Introduction}

Competition among businesses has undergone significant changes owing to big data (BD) analytics - a novel method of pattern extraction from a set of raw information - contributing to making proper decisions, enhanced productivity, innovation upgrades and knowledge generation [1,2]. It is generally viewed as a significant company asset that has been the focus of decision-makers to obtain timely insights and generate a high revenue level [3,4]. $B D$ reflects the interactions among employees and customers stored in the system of the organization, which eventually furnishes actionable, predictive, descriptive as well as prescriptive outcomes [5,6]. Because of the high volume of BD, in the form of high velocity and various information assets, valuable knowledge and information extraction from it remains full of complexity [7]. 
$\mathrm{BD}$ is one of the most-implemented technologies for an organization in order to create and attain a superior competitive position. BD as an important technology is, generally, defined as "a collection of subject-oriented data with information from a specific time period that assists the management decision-making process" (p. 162 [3]). According to the International Data Corporation [8], the global market of BD was worth USD 66.2 billion in 2020, and is forecasted to reach USD 157.2 in average annual growth until 2026. Many businesses consider the adoption of BD to be essential and they believe that it has strong potential [2,9]. However, despite the theorized benefits of BD deployment, numerous works found that not all businesses are adopting BD. For example, Choi et al. [10] pointed out there is a suspicious viewpoint that $80 \%$ of the businesses will fail to tap into BD if they progress with no clearly defined strategic goals. Lately, in the majority of companies, the adoption of BD is relatively low [11]. Many businesses have not achieved integrated use beyond the initial adoption process [10]. Although adoption of BD is getting attention as a means to create impacts, such as the establishment of new business areas and business optimization, a limited number of businesses have adopted it and obtained the appropriate values [12,13].

Prior related works on the topic shows that firms do reap advantages from adopting BD as a solid base to enhance their performance [14-18], with the majority of them reporting a positive BD success-business impact relationship [19]. Large firms have employed the BD based on its values for varying purposes, including but not limited to the prediction of new market trends and assessing the behavior and experiences of customers to determine new enhancement opportunities. In the case of SMEs, although they are major contributors to the economy of the nation, they are left far behind when it comes to BD implementation, owing to their limited resources and lack of understanding as to the main barriers that prevent BD adoption and use [14,20-22]. A review of the literature shows that studies dedicated to adoption of BD among SMEs are still few and quite limited [12,15,23]. Hence, the present work employs a technological, organizational and environment (TOE) framework to examine BD adoption drivers among the SMEs sector. The TOE model is appropriate to be utilized in this case owing to its flexible nature in explaining the technology adoption levels among these enterprises [24,25].

Extensive existing studies concerning the effects of TOE factors on technologies / innovations adoption are available [26,27], but the findings are inapplicable and ungeneralizable to SMEs' BD adoption, owing to the fact that the TOE model's factors are influenced and determined by the technology type, the firm's size and the context of the study $[12,28,29]$. In relation to these reasons, each technology possesses distinct characteristics and factors influencing its adoption success. Empirical findings found in the literature regarding technology adoption were revealed to have different TOE factors influencing the adoption of numerous technologies/innovations [30]. For example, while a relative advantage was found by Wahab et al. [4] and Sun et al. [29] as a significant IT/IS innovation adoption driver, Lutfi et al. [31] and Yoon and George [32] evidenced its insignificant effect on the adoption of IT-related innovations. Moreover, the TOE factors' influence differs with business size, with many findings show the inapplicability of large organizations' outcomes to smaller-sized organizations (e.g., SMEs) [33]. In addition, distinct differences in structure, resource availability, environment, and technological infrastructures of large-sized firms and SMEs influence the TOE factors' influence on the decision to adopt technology [25]. According to Alharbi et al. [28], various environmental situations and country requirements are top determinants of the level to which the influence of TOE factors can be experienced in firm adoption of technology. Thus, a new model is required to shed light on SMEs' BD adoption drivers [12].

Evidently, there is a need to examine and understand BD adoption drivers owing to the fact that it is a new topic with a lack of empirical findings; thus, systematized knowledge in the area is required [12]. In a related study, following a systematic literature review, Al-Sai et al. [12] found two major research gaps, the first being the limited studies of BD and their general conceptual nature, which calls for additional empirical studies to enrich 
the literature The second research gap is the focus of the majority of studies on developed nations in the continents of Europe and North America [34], with only a few addressing $\mathrm{BD}$ barriers in developing countries in the Middle East [35,36]. However, it would suffice and be worthwhile to mention that several authors have highlighted the need to examine $\mathrm{BD}$ in different contexts $[4,37,38]$, particularly in the case of developing nations, to enrich the extant literature $[10,12]$. Considering this recommendation, this study is an attempt to contribute to the literature on the TOE factors that influence SMEs' adoption of BD and the study's findings are expected to assist SMEs decision-makers in understanding the antecedents of BD adoption success as well as the vendors and policymakers in promoting the technology within such enterprises.

The organization of the paper is as follows: the present section is followed by Section 2, containing the literature review of $\mathrm{BD}$; Section 3 provides the theoretical framework and hypothesis development, the sampling procedure and the process of data collection; Section 4 provides details of the methodology adopted; Section 5 is a summary of the data analysis; and, finally, the last sections deal with discussing the findings and the recommendations and conclusions.

\section{Literature Review}

Progress and developments in social networking, e-commerce websites, advanced mobile technologies, search engines and new digital technology have resulted in an increasing amount of $\mathrm{BD}$, which is paving the way for firms to produce and capture data that have the three Vs characteristics, namely, variety, velocity and volume $[39,40]$. Variety describes the various data forms that cannot be managed through traditional analytical system due to its complication, and these include unstructured, semi-structured and structured data [4]; velocity describes the speed of data production and analysis in real-time [41]; lastly, volume describes the considerable data amount that the firms collect to sift through for information and data patterns, which hold important knowledge [20]. According to Mikalef et al. [17], the concepts and meaning of big data, BDA capabilities (BDAC), and the BDA differ, although researchers use them synonymously in their writings. Their findings revealed that some studies focused on the characteristics of the data, while others developed the 'analytics' definition as a term that stresses the process, tools and methods for data analysis. The BDAC definition may surface after the focus shifts from to the effect of big data hidden values obtained through analytical methods. The big data features, namely, variety, velocity and volume, urge companies to encapsulate insight from it considering that traditional methods are unfeasible [15].

There are several existing studies concerning the adoption of BDA in SMEs. For instance, Ajimoko [42] have analyzed the main criteria for the adoption of cloud-based big data analytics based on three models, which are diffusion of innovation theory, the technology acceptance model and the technology-organization-environment framework. The study results classified the significant adoption criteria into two categories, internal and external. The internal criteria included technological and organizational factors, which play a critical role in the adoption of BDA; the external criteria consisted of vendor-related and environmental factors with less effect on the adoption of BDA. On the other hand, Mangla et al. [43] examined the role of BDA on project performance using SEM method. The authors proposed a framework to analyze the effect of nine factors, including project operational capabilities, social responsibility, environmental technologies, green purchasing and a project knowledge management focus, on sustainability, top management, project success, explorative learning, collaboration and project complexity. The results revealed that the use of BDA would improve the project performance as well as the nine factors in the manufacturing sector. Similarly, Nasrollahi, Ramezani and Sadraei [44] have studied the influence of BDA on SMEs' performance in organizations in Iran. The findings of this study showed how to help organizations in developing countries to adopt BDA components in order to enhance their performance. In addition, the study results found that 12 factors had a significant effect on the adoption of BDA, including social perfor- 
mance, economic performance and operational performance. In a recent study conducted by Maroufkhani et al. [45], they have examined the critical drivers for the adoption of BDA and impact of BDA on SMEs' performance in Iran. The researchers have found that seven factors, including top management support, observability, trialability, uncertainty and insecurity, complexity, external support and organizational readiness, had a strong effect on the adoption of BDA in Iranian small and medium organizations. In addition, they found that the use of BDA would enhance the performance of these firms effectively. In Korea, Park et al. [46] have conducted a study to identify the significant aspects of the adoption of BDA. Based on the study results, the adoption factors were classified into three key aspects, which are environmental factors, organization factors and technological factors. In the same way, Skafi, Yunis and Zekri [47] have studied the decision to adopt BDA in Lebanese firms by applying the TOE and the contextual theory. The results revealed that technological factors such as security and complexity had a positive effect on the adoption of BDA. In addition, the results showed that organizational factors, including prior IT experience and top management support, had a strong impact on the decision of BDA adoption. In turn, lack of government initiatives and poor infrastructure had a negative effect on BDA adoption. In Malaysia, Loh and Teoh [48] have focused on studying BDA adoption during Covid-19 in order to help firms to improve their performance and overcome the challenges during the lockdown. The study examined the impact of technological factors on BDA adoption among Malaysian SMEs. The study identified the most important technological aspects that could encourage Malaysian firms to adopt and use BDA effectively. A study conducted in USA by Parson [49] studied IT experts' decision to adopt BDA in SMEs using the TAM model. The study findings found that BDA adoption was significantly affected by perceived usefulness and perceived ease of use. Finally, Mikalef et al. [50] explored the impact of BD adoption on competitive performance indirectly by the mediation of dynamic capabilities among Norwegian firms. The results indicated that two types of operational capabilities, namely, marketing and technological capabilities, had a positive effect.

\section{Theoretical Framework and Hypothesis Development}

In our study, we propose a hybrid model by employing the technological-organiza tional-environmental (TOE) model and diffusion of innovation theory (DOI) as the theoretical foundation. Several studies mentioned that the use of TOE and DOI models would help researchers to examine the adoption of IT in SMEs [27,51]. For instance, the DOI model focuses on the role of technological attributes as important for IT adoption in organizations [29]. On the other hand, the TOE framework explains the factors (internal and external) that may affect the technology adoption of firms [32,52]. Based on the above, integrating the DOI model with the TOE model will lead to propose a comprehensive framework in order to highlight the most important drivers that help SMEs to adopt BD successfully.

Accordingly, this study builds on the prior studies concerning BD and TOE factors for technology adoption and proposes a conceptual model (see Figure 1). There are several TOE factors that have been proven to influence technology adoption, but in this study, the authors focus on the technological factors (relative advantage, complexity, compatibility and security), organizational factors (top management support and organizational readiness) and environmental factors of competitive pressure and government regulations. The next sub-sections are dedicated to providing the rationale for the anticipated hypotheses. 


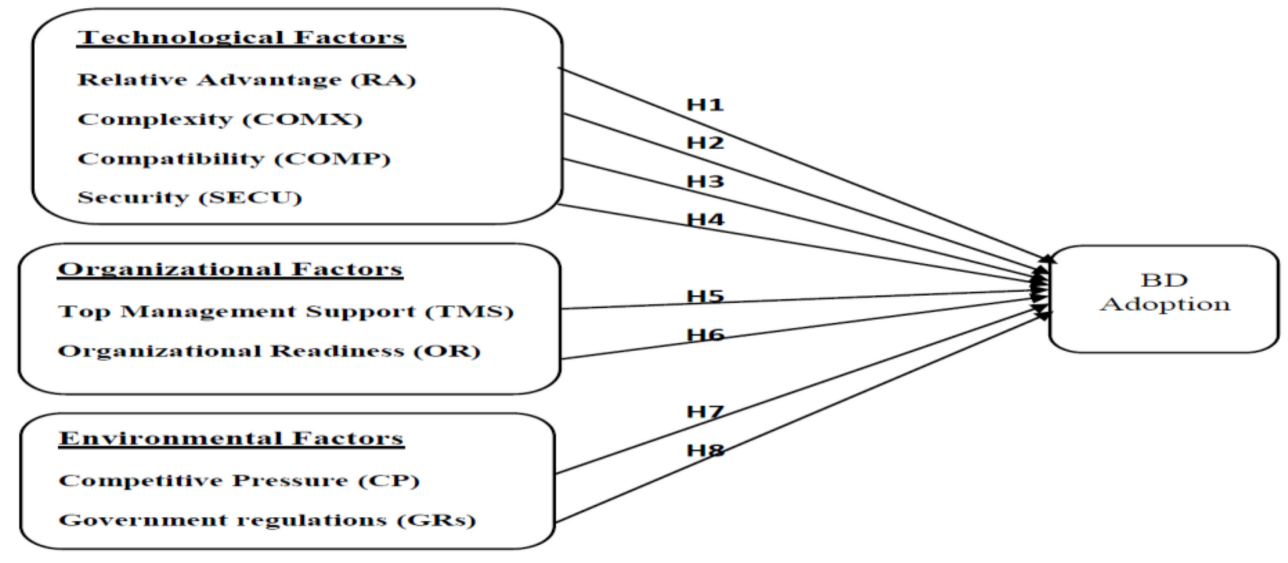

Figure 1. Research model.

\subsection{Technological Context}

Studies in the literature $[53,54]$ have stated that the technological context in the TOE model sheds light on the technology's exogenous and endogenous elements in terms of its adoption, with one of the elements having a relative advantage. Stated clearly, the perceived advantage of innovation to the value of a specific organization may significantly affect the intention of the organization to adopt it $[4,55]$. Basically, the relative advantage refers to the level to which technology adoption is perceived as dominant to other existing technology types used in businesses, and the benefits that the company can obtain from it [56,57]. According to Lutfi et al. [58], SMEs are inclined towards technology adoption if they are convinced that its advantages are more than that of any other existing technology; thus, the current work proposes the following hypothesis for testing:

Hypothesis 1 (H1). Relative advantage of BD has a positive influence on its adoption.

According to Rogers [54], new technology adoption or new system adoption may end up in failure if it is considered as being too complicated and hard to adopt. Technological challenges arise when, for instance, the processes of working together is altered so the new technology has to have ease of use for easy adoption [59]. It is important for employees to attain an understanding of the innovation in a timely manner, because sophisticated technologies bring uncertainty and complexity to their adoption. Based on prior studies, complexity is a significant factor in innovation implementation $[60,61]$, and as such, innovation adoption is always debatable among decision-makers [59,62]. In comparison to other innovation technological elements, complexity has been evidenced to have a negative effect on technologies adoption [57]. Recent studies on complexity's influence over the $\mathrm{BD}$ adoption revealed its negative influence over the latter [63,64]. In other words, if SMEs are convinced that adopting innovation would need significant effort, then they will have a lower likelihood towards its adoption. Thus, the present work suggests the following hypothesis:

Hypothesis 2 (H2). High level of BD complexity has a negative relationship with its adoption.

Compatibility is the level to which a new system is aligned with the company's current system [65], and in technology adoption, compatibility is reflective of the technology's alignment with the organization's business practices and culture [5]. Compatibility has been evidenced to be among the top technology adoption drivers [53] and empirical evidence showed that compatibility is among the major influential determinants in determining $\mathrm{BD}[63,66]$. In this regard, organizations can increase their elasticity in procedures and policies to facilitate a positive compatibility-BD adoption relationship [63]. Thus, in this study, it is argued that SMEs will have the likelihood to accept and adopt BD in different 
departments if they are convinced that its adoption is consistent with their current standards and procedures; therefore, this study proposes the following hypothesis:

Hypothesis 3 (H3). Compatibility of BD has a positive relationship with its adoption.

Another technological element considered in this study is security and it refers to the risk relating to the adoption of innovation, which prevents innovation adoption in the organization [67]. In a related study, Asiaei and Rahim [60] stated that data-related innovation adoption requires the assurance of security. For instance, Alshamaila et al. [67] mentioned that in cloud computing, security concerns regarding BD has been emphasized. Cloud computing is basically a host for BD; thus, privacy and security area issues, which are invariably connected with cloud computing nature and data, are predictors of adopting BD $[64,68,69]$. In addition, security is the top concern of business owners when it comes to data-related services adoption $[60,62]$. Based on this point of view, a security concern is the risks that are present in outsourcing, linked to the usage of third-party tools and support in providing a BD solution or cloud computing services adoption [70].

In relation to the above, firms that are inclined towards reaping big data benefits for their businesses require outsourcing the whole or part of the big data initiatives. The majority of firms turn to outsourcing due to their lack of capacity to develop and maintain a BD environment in their firms, and sometimes, they need support because of their lack of knowledge and innovation on BD-related technologies [64]. Outsourcing is what could bring the security or privacy into light as it calls for the sharing of firm data with vendors and external suppliers, exposing the firm to losing control of confidential information. In this study, it is argued that security significantly affects BD adoption; thus, it proposes the following hypothesis:

Hypothesis 4 (H4). High level of BD insecurity has a negative relationship with its adoption.

\subsection{Organizational Context}

This study examines the management support and organizational readiness as the organization attributes that influence BD adoption among SMEs. First, top management is the level to which managers understand and accept the new technology capabilities [71]. SME decision-makers are more likely to be comprised of a top-management group (team) and their commitment/support is necessary for innovation adoption/acceptance success [72]. The top-management team facilitates the connection between individuals and innovation adoption as the willingness to adopt is related to their level of innovativeness. However, prior studies have supported the role of top-management support as a critical driver of new technology adoption $[27,67,73]$. In turn, top managers in SMEs were reported to have a lack of willingness in new system implementation in several prior studies [74]; therefore, this study proposes the following hypothesis for testing:

\section{Hypothesis 5 (H5). Top management support has a positive relationship with BD adoption.}

Another organizational element considered in this study is organizational readiness, which is, according to Gangwar [63], the firm's ability and inclination towards new technology adoption. It is the capability of the firm to manage and invest in new technology adoption, which include but are not limited to technical IT expertise and capabilities [32]. In the case of big data and business analytics, academics are of the consensus that readiness of organization is necessary for BD adoption [4,63]. Organizational readiness in SMEs has been evidenced to have a significant association with new technology adoption in prior studies $[58,60]$. Therefore, this study argues that, for BD adoption, organization readiness is among the top critical drivers, and as such, it proposes the following hypothesis for testing:

Hypothesis 6 (H6). Organizational readiness has a positive relationship with BD adoption. 


\subsection{Environmental Context}

Under the environmental context, the factors comprise the elements external to the organization [75], which is in the dynamic external ecosystem of the organization that it is sensitive to. Based on the TOE framework, both competitive pressures and governmental regulations fall under the external elements that have the potential to affect the adoption of BD among SMEs. More specifically, competitive pressure was defined as the external environment's effects on the firm that urges it to use BD [5]. In essence, competitive pressure is felt by the firm from its suppliers, customers and competitors. Prior studies focused on SMEs stated that the pressure for firms to compete turn them to adopting new technology $[27,60]$. In a related study, several studies indicated that competition has a significant effect on technology adoption among SMEs [76]. In addition, in Egyptian SMEs, environmental pressure stemming from media, rivals and customers had a significant effect on their sustainable manufacturing practices. Other studies, such as those by Chen et al. [77] and Lautenbach et al. [78], found that increasing BD usage among competitors could work to pressurize the owners and managers to capture business analytics and intelligence to obtain and maintain a competitive market status. Hence, this study proposes the following hypothesis for testing:

Hypothesis 7 (H7). Competitive pressure has a significant positive relationship with BD adoption.

Moving on to government regulations, which is the second environmental element that influences BD adoption, such regulations may prohibit firms from or encourage them towards adopting new technologies [58,79]. Firms' adoption of BD may increase if government rules and policies encourage them towards it and if technological standards and legislation are in favor of it $[64,80]$. Organizations facing high level of government pressure and regulations have the likelihood to adopt cloud technology based on prior studies $[4,64,81]$. Thus, based on the above literature review of BD adoption studies, government regulations in the form of assistance and incentives stimulate the adoption/acceptance of BD; thus, this study proposes the following:

Hypothesis 8 (H8). Government regulation has a significant association with BD adoption.

Figure 1 highlights the proposed conceptual model.

\section{Methodology}

In this study, a quantitative questionnaire was used for collecting the data. The measurement items were adopted from previous studies as presented in Appendix A. The current study employed a 5-point Likert scale with anchors that ranged from one (1), depicting strongly disagree, to five (5), depicting strongly agree. The initial questionnaire version was forwarded to four academicians and three experts of BD from the industry for perusal and on the basis of their feedback, the questionnaire items were tweaked when necessary, after which the questionnaire was tested through a pilot study. The respondents' communication medium was Arabic and, as such, the questionnaire was translated from English to the Arabic language using the services of a language professional, after which SME experts in Jordanian SMEs perused it for any inconsistencies. Three experts perused the translated version to make sure that the items were accurate in their measurement of the variables in SMEs. The translation method employed was back-to-back translation to maintain the meanings of all the items, and prior to collecting the data from the actual study population, the translated questionnaire was tested on 37 SMEs owners/managers to ensure questionnaire clarity and to test the constructs' reliability, following the suggestion of Dwivedi et al. [82]. The constructs' Cronbach's alpha all exceeded 0.70, which, according to Hair et al. [83], indicates a good reliability level.

In this research, the research hypotheses were constructed from the previous studies in the literature. The items measuring BD adoption were specifically adopted from $\mathrm{Tu}$ 
(2018) and the exogenous factors were divided into technological, organizational and environmental variables in the TOE model. Included in the technological factors were four constructs and they were relative advantage (RA), complexity (COMX), compatibility (CPMP) and security (SECU), and the items were obtained from $[64,77,84,85]$. Added to the above, the organizational factors of top-management support (TMS) and organizational readiness (OR) were measured by items obtained from [77], while the environmental factors of competitive pressure (CP) and government regulations (GRs) were measured using items obtained from $[64,86]$. The entire items and their sources are detailed in Appendix A.

As mentioned, the population of this study consists of manufacturing Jordanian SMEs, numbering a total of 2210 enterprises [87]. The respondents consisted of the SMEs owners/managers, as they are the individuals holding information concerning the topic under study. The researcher initially contacted the firms to shed light on the study purpose and the meaning of $\mathrm{BD}$, after which the names of the potential respondents and their email addresses were obtained. Using their email addresses, the survey questionnaire was sent to the respondents online, with each survey including a cover letter that explained the study objective and purpose and a short overview of BD. A total of 500 questionnaire surveys were distributed but only 123 were retrieved, from which seven were deemed incomplete or had not met the inclusion conditions and, as such, there were 116 useable questionnaires in total, indicating a response rate of $23.2 \%$. The next step involved the testing of non-response bias by comparing early and late responses through the use of a $t$-test. Based on the results at the significance level of $5 \%$, no statistical differences existed between the two responses, which support the absence of non-response bias, following King and He's [88] study.

\section{Data Analysis}

This study used the PLS-SEM approach for hypothesis testing. PLS-SEM is a multivariate statistical approach that permits for the simultaneous estimate of multiple associations between one or several exogenous constructs and one or several endogenous constructs in a single model. This modelling technique also works efficiently and allows analyzing complex models, containing moderating or even mediating relationships variables, and with relatively smaller sampling sizes [83,89-92]. Based on the abovementioned explanations, we employed PLS-SEM techniques for testing the posited hypotheses to analyze the data collected. This is because this study model contains nine latent constructs, which increase the complexity of the proposed model. Moreover, the responses received was 116 in this study, which is fewer than the required values that are essential to apply other approaches. Finally, the nature of this research is explorative and applies DOI and the TOE framework. This integration requires employing a path-modelling technique in response to several researchers' recommendation that if the research is an extension of an existing theory or of a prediction-oriented nature, then the PLS-SEM technique should be used [83]. Through this technique, the variables validity and reliability were verified after which the structural model was analyzed.

\section{Results and Interpretation}

\subsection{Assessment of Measurement Model}

Measurement model assessment is the prerequisite and the first step in generating findings in PLS-SEM. It is about exploring of measurements' validity and reliability. The measurement model assessment in PLS-SEM varies depending on the nature of the measurement model, whether it includes formative or reflective measures. Generally, the reflective measurement model supposes that the indicators are initiated by the construct itself (interchangeable) and all indicators measure a similar causal phenomenon. In contrast, the formative measurement model supposes that indicators cause a construct of interest. Therefore, the formative indicators are not interchangeable and are dropped as an indicator of the variable. Thus, due to such variances, every measurement model has dissimilar criteria compared to one another. In the reflective measurement model, constructs convergence, 
factor loadings, composite reliability and discriminant validity are the main concerns. On the other hand, if the case is a formative measurement model, the key interests are to test the co-linearity, indicator weights significance and relevance.

However, the nature of the measurement for all variables are reflective in the present research where dependent, and independent variables were estimated through reflective measures that were adopted from earlier related studies (see Appendix A) and treated as individual items. Therefore, under this assessment step, the constructs convergence, their factor loadings, Cronbach alpha values, composite reliability and AVEs (average variance extracted) were tested, with the following criteria, respectively: 0.7, 0.5 and 0.7, according to Hair et al. [83]. The constructs were found to meet the criteria and illustrate a good convergent validity level (refer to Table 1). The discriminant validity was also tested using Fornell-Larcker criterion [93], and it was revealed that the inter-construct correlations did not exceed the squared AVEs (refer to Table 2). This is indicative of good level of discriminant validity of the constructs [93].

Table 1. Relevant indicators of the measurement model.

\begin{tabular}{cccc}
\hline Latent Construct & $\begin{array}{c}\text { Cronbach } \\
\text { Alpha }>\mathbf{0 . 7 0 0}\end{array}$ & $\begin{array}{c}\text { Composite Reliability } \\
\mathbf{> 0 . 7 0 0}\end{array}$ & $\begin{array}{c}\text { AVE } \\
\mathbf{0 . 5 0 0}\end{array}$ \\
\hline BD adoption & 0.814 & 0.848 & 0.653 \\
RA & 0.826 & 0.865 & 0.562 \\
COMX & 0.831 & 0.867 & 0.686 \\
COMP & 0.843 & 0.872 & 0.629 \\
SECU & 0.808 & 0.838 & 0.633 \\
TMS & 0.899 & 0.929 & 0.765 \\
OR & 0.868 & 0.900 & 0.692 \\
CP & 0.845 & 0.878 & 0.708 \\
GS & 0.865 & 0.897 & 0.636 \\
\hline
\end{tabular}

Table 2. Correlations among the latent constructs (AVE square root).

\begin{tabular}{|c|c|c|c|c|c|c|c|c|c|}
\hline & RA & COMP & COMX & SECU & GS & BD adop & TMS & OR & CP \\
\hline RA & 0.749 & & & & & & & & \\
\hline COMP & 0.381 & 0.885 & & & & & & & \\
\hline COMX & -0.401 & -0.487 & 0.896 & & & & & & \\
\hline SECU & -0.266 & -0.333 & 0.378 & 0.795 & & & & & \\
\hline GS & 0.124 & 0.185 & 0.174 & 0.307 & 0.797 & & & & \\
\hline BD adop & 0.700 & 0.711 & 0.840 & 0.641 & 0.492 & 0.808 & & & \\
\hline TMS & 0.406 & 0.486 & -0.613 & -0.361 & 0.528 & 0.546 & 0.875 & & \\
\hline OR & 0.431 & 0.500 & -0.685 & -0.250 & 0.468 & 0.650 & 0.678 & 0.832 & \\
\hline $\mathrm{CP}$ & -0.099 & 0.063 & 0.078 & -0.050 & 0.133 & -0.015 & -0.058 & -0.118 & 0.839 \\
\hline
\end{tabular}

Note: The values in bold represent the square root of the AVE.

\subsection{Assessment of the Structural Model}

In this study, the proportion of variance explained was used for evaluating the internal validation by examining the value of the coefficient of determination (R2) [83] of the proposed model, and the $\mathrm{R} 2$ of $\mathrm{BD}$ adoption is 0.561 , indicating that the determinants explain $0.561 \%$ of the variance in $\mathrm{BD}$ adoption, representing a moderate to moderate predictive power [83]. Predictive relevance was measured using Stone-Geisser Q2 (crossvalidated redundancy) following Chin [94] and the Q2 values of BD adoption exceeded zero (0), indicating a satisfactory fit of the model. The structural model was assessed using a bootstrapping technique with 5000 resamples, as recommended by Hair et al. [83]. The results tabulated in Table 3 revealed that complexity and security had a negative effect on BD adoption ( $\beta=-0.170, p<0.001$; and $\beta=-0.122, p<0.01$, respectively). The results also showed that RA, TMS, OR and GRs had a positive effect on BD adoption ( $\beta=0.219$, $p<0.01 ; \beta=0.228, p<0.001 ; \beta=0.100, p<0.05$; and $\beta=0.309, p<0.001$, respectively). On the other hand, the results did not support the significant effect of COMP $(\beta=0.051$, $p>0.05)$ and $\mathrm{CP}(\beta=-0.011, p>0.05)$ on $\mathrm{BD}$ adoption. In other words, with the exception of $\mathrm{H} 2$ and $\mathrm{H} 7$, the hypotheses were all supported. 
Table 3. Result of the hypotheses testing of the direct relationship model.

\begin{tabular}{ccccc}
\hline Hypothesis No. & Relationship & Path Coefficient & St-D & T-Value \\
\hline H1 & RA $\rightarrow$ BD adoption & 0.219 & 0.078 & $2.870 * *$ \\
H2 & COMX $\rightarrow$ BD adoption & -0.170 & 0.053 & $3.101 * * *$ \\
H3 & COMP $\rightarrow$ BD adoption & 0.051 & 0.052 & 0.871 \\
H4 & SECU $\rightarrow$ BD adoption & -0.122 & 0.044 & $2.738^{* *}$ \\
H5 & TMS $\rightarrow$ BD adoption & 0.228 & 0.054 & $4.319^{* * *}$ \\
H6 & OR $\rightarrow$ BD adoption & 0.100 & 0.059 & $1.801^{*}$ \\
H7 & CP $\rightarrow$ BD adoption & -0.011 & 0.043 & 0.182 \\
H8 & GR $\rightarrow$ BD adoption & 0.309 & 0.066 & Supported \\
\hline
\end{tabular}

Note: Significant at ${ }^{*} p<0.05,{ }^{* *} p<0.01$ and ${ }^{* * *} p<0.001$ (one-tailed test).

\section{Discussion and Conclusions}

In our study, we focused on investigating the BD analytics adoption among SMEs in Jordan. In the case of BD adoption among the SMEs studies here, the findings from the technological factors demonstrated that RA had significant effects while compatibility had no significant effect-in this regard, the significant influence of RA on BD adoption is consistent with the previous results that reported the substantial effect of RA. Because the advantages provided by BD are the basic drivers or motivators for SMEs to accept it, they are more likely to have a great influence on its adoption. In other words, being aware of $\mathrm{BD}$ advantages is enough to adopting even if the SMEs are faced with financial issues, IT infrastructure problems and a lack of a skilled workforce. RA has been evaluated as the most influential factor in the acceptance and adoption of IT/IS systems or services [95]. Unfortunately, compatibility's insignificant effect on BD adoption is inconsistent with the findings of prior studies, including Lutfi et al. [31] and Park and Kim [96]. Such an insignificant effect may be explained by the adjustability level of the SMEs' procedures and practices, which could be easier for the SMEs compared to large-sized organizations. SMEs are more flexible as a result of which computability between their practices and BD system is a non-issue regarding their decision-making process.

On the other hand, other related prior studies, such as Gangwar [63] and Lai et al. [64], reported the negative effects of complexity on BD adoption among SMEs, while Asiaei and Rahim [60] explained that innovation adoption among SMEs is difficult because of their need for internal expertise. Because of such difficulty, managers illustrate a lack of confidence in the skills and abilities of workers to successfully adopt BD. If this is the case, then SMEs should outsource their BD adoption process.

Moreover, security was also supported to have a negative effect on BD adoption in this study. According to Priyadarshinee et al. [70], security has been evidenced by prior studies as top concerns of business owners when it comes to data-related technologies adoption. SMEs notably turn to outsourcing BD but the risk of losing confidential data and information leakage to their rivals may have an adverse impact on their adoption, which is why BD service providers need to build SMEs confidence and trust in their services. Building trust is generally brought about by the service provider reputation or the clients prior experiences with the same [97]. This suggestion for building trustworthiness of clients by service providers was supported by Bush, Tiwana and Tsuji [98], who indicated the importance of the providers relaying their reputation for security and positive referrals from prior clients. Kim and Ko [99], on the other hand, recommended that the service provider's good reputation could be reinforced through social media marketing.

In the case of organizational factors of TMS and OR, the findings of this research confirmed their significant effect on BD adoption. Prior studies have consistently showed TMS as a significant element of SMEs when it comes to adopting various technology types $[27,33,60,73]$. Owing to the role of the SMEs' owners/managers as decision makers, it is logical to state that they need to develop a supportive ecosystem to bring about adoption success [58,100]. In fact, managers motivate organizational changes through their values communication and their vision clarification to the subordinates [59]. Suffice it 
to say that top-management support can bring about technology learning and diffusion throughout the organization, and thus plays a key role in its various adoption stages.

Moving on to the significant relationship between OR and BD adoption, this has been frequently supported by studies dedicated to technology adoption among SMEs [27,59,64]. Lack of IT infrastructure, skilled human and financial resources act as barriers to BD adoption among SMEs. As such, enterprises may have no likelihood to adopt it without sufficient capabilities and resources.

Concerning environmental factors, government regulations were found to have a significant effect on BD adoption in SMEs but competitive pressure was not. First, the insignificant result found for the competitive pressure effect on technology adoption is in contrast with those reported by prior studies [101-103], and in alignment with Wahab et al. [4]. In the context of Jordan, a lack of multinational rivals and low BD levels among local rivals are some of the potential reasons behind such an insignificant effect. Additionally, because of the current pandemic, multinational firms steer clear from investing in the Jordanian market, as a result of which they are not as affected by globalization. The low BD adoption levels in Jordanian local firms have led to less competitiveness among them, particularly SMEs, which explains the insignificant role of the construct on the decisions towards BD adoption.

Finally, the significant government regulations-BD adoption relationship found in this study is consistent with that reported by prior related studies $[4,64,104]$. More specifically, Lutfi [105] contended that the SMEs CEOs' recognition of government support and incentives play a key role in meeting the enterprises' IT innovation adoption and would lead to their prompt adoption. In the same line of argument, government regulatory support and financial incentives can ensure that a lack of financial and technical skills for BD adoption among firms is resolved. In fact, government regulations facilitate the decisions of SMEs when it comes to adoption, particularly when the enterprises have insufficient resources.

\section{Contributions}

This study has several contributions from the theoretical side, with the main one being the resolution of questions when it comes to the BD drivers among SMEs because the majority of studies dedicated to BD adoption were focused on large-sized firms. The systematic review [25] revealed a lack of studies focused on the SMEs' BD adoption, and because of the differences between SMEs and large-sized firms in light of resources availability and size, this study explored the TOE factors that could determine the adoption of BD among Jordanian SMEs. This study contributes by proposing a distinct model concerning the TOE factors role on BD adoption. Based on the obtained findings, RA, complexity, security, TMS, $\mathrm{OR}$ and government regulations have roles to play in convincing managers/owners of SMEs to adopt BD, whereas compatibility and CP had no such role because of their insignificant effects. Some of the results in this study are in contrast to those of prior findings as the latter mainly focused on large-sized firms, which only serve to support the argument that the BD adoption drivers in SMEs differ from those of their larger counterparts.

The study findings show that TOE factors do influence BD adoption among SMEs, with the top among them being top-management support and government regulations. First, top-management support comes in the form of sufficient financial and technical support, employment of suitably skilled employees and provision of relevant training for current employees, searching for competent BD vendors and appropriating adequate resources for BD implementation. It is important that top management stimulate BD awareness as a strategic firm priority and promote its relevant initiatives for its high utilization within firms. Top-management commitment to the entire business activities actually plays the role as a proxy for adopting BD among SMEs and ensures a high success level of adoption. In this regard, the governments should create awareness initiatives for SMEs superiors concerning advantages of BD usage to obtain their commitment and their full support.

In relation to the above, insufficient financial resources, lack of required skilled work force, capability and IT infrastructure can prevent BD adoption; thus, these barriers have to 
be addressed by the collaboration between $\mathrm{BD}$ vendors and the government. A suitable short-term solution would be for $\mathrm{BD}$ vendors through providing online activates to SMEs, such as a training workforce to meet the need for skilled BD. Moreover, the governments can provide data analytics-related initiatives to resolve the same issue in the long-term and $B D$ vendors can provide sufficient technical support to businesses and offer them affordable solutions through reasonably priced packages. Furthermore, vendors of BD can also provide technical support for operators to improve their capabilities of usage and to address and resolve complex activities carried out through the system.

The resulting significant effect of complexity and security sheds light on the importance of the BD vendors' reputation, particularly when it comes to offering security and a trial version of the system as well as providing a sufficient level of technical training and support to promote BD. This is because BD is costly and this along with the deficiency in the appropriate technical skills workforce of the SMEs could turn the enterprises to opting for outsourcing. Both complexity and security concerns appear to be the primary barriers behind the non-adoption of BD or delayed adoption among SMEs and, therefore, it is crucial for vendors to offer trial versions as well as technical and training support to resolve these issues. In this regard, a trial BD version would enlighten the SMEs as to the system's benefits and train them in how to run analytical methods and eventually mitigates their level of uncertainty and complexity perception. Vendors need to amplify their good reputation to obtain the trust of SMEs and this can be possible through social media marketing and referrals.

Reverting back to top-management support in adopting BD, vendors can use other previous clients as examples of success stories to promote the interest and inclination of the decision makers (top management) towards BD adoption. Such a presentation and clarification could involve the provision of the penetration rate in the market. On the other hand, RA and compatibility had insignificant relationships with BD adoption, highlighting their minimal role in forming the managements' /owners' decisions to adopt BD—in this case, their role need not be emphasized by the BD vendors to SMEs.

\section{Limitations and Future Studies}

Similar to other empirical studies of its caliber, this study has its own limitations that may influence the results' generalization. The first limitation pertains to the sample population, which is confined to SMEs. This type of enterprise has distinct resources and structural flexibility when compared to their larger counterparts and, thus, future studies are suggested to study the proposed model on large firms. The second limitation pertains to the focus on Jordan under the Covid-19 pandemic - generally known to influence the market's competitive nature and the government authority to support BD adoption among firms. In this regard, future studies can apply the research framework among SMEs in other developing and developed nations other than Jordan. The third limitation is related to the cross-sectional nature of the study, where the formulated hypotheses are tested with the use of questionnaire survey results. This method confines the demonstrability of causality in the variables' relationships, in that the study nature is not able to conduct a detailed observation of the dynamic changes in the adoption of BD. This can be addressed through a longitudinal study testing the relationships over a longer period of time for greater detailed observations and an accurate outcome. Lastly, future studies may use this study's framework and include additional potential factors such as the providers' support, organizational culture and peer influence, or even by adding and verifying whether the resulting scores of the BD use are not significantly related to control variables such as firm size, firm age, sector, etc.

Author Contributions: Conceptualization, A.L., A.A. and M.S.; Formal analysis, A.A.; Investigation, A.A.K.A.; Methodology, M.A.A.; Project administration, N.I.; Resources, N.I. and M.S.; Software, M.A.A.; Supervision, A.L.; Writing-original draft, A.L.; Writing—review \& editing, M.A. and A.L.A.-K. All authors have read and agreed to the published version of the manuscript. 
Funding: This research was funded through the annual funding track by the Deanship of Scientific Research, vice presidency for graduate studies and scientific research, King Faisal University, Saudi Arabia [project no. AN000578].

Institutional Review Board Statement: Not applicable.

Informed Consent Statement: Not applicable.

Data Availability Statement: The data presented in this study are available on request from the corresponding author.

Conflicts of Interest: The authors declare no conflict of interest.

\section{Appendix A}

\begin{tabular}{|c|c|c|}
\hline Variable & Measurements & Source \\
\hline BDA adoption & $\begin{array}{l}\text { Our business intends to adopt BD } \\
\text { Our business intends to start using } \mathrm{BD} \text { in regular bases in the future } \\
\text { Our business would highly recommend BD for others to adopt. }\end{array}$ & $\operatorname{Tu}(2018)$ \\
\hline $\begin{array}{l}\text { Relative } \\
\text { advantage }\end{array}$ & $\begin{array}{l}\text { BD enables our business to appropitately manage supply chain } \\
\text { risks. } \\
\text { BD enables our business to minimize all types of waste throughout } \\
\text { the warehousing operations. } \\
\text { BD would enable our business to respond faster than competitors } \\
\text { would to changing environments. } \\
\text { BD would enable our business to minimize total product cost to } \\
\text { final customers. } \\
\text { BD would enable our business to deliver product precisely on-time } \\
\text { delivery to final customers. }\end{array}$ & $\begin{array}{l}\text { Agrawal } \\
\text { (2015) }\end{array}$ \\
\hline Compatibility & $\begin{array}{l}\text { Using BD is consistent with our business practices. } \\
\text { Using BD fits our organizational culture. } \\
\text { Overall, it is easy to incorporate BD into our business. }\end{array}$ & $\begin{array}{l}\text { Chen et al. } \\
(2015)\end{array}$ \\
\hline Complexity & $\begin{array}{l}\text { Learning to use the } \mathrm{BD} \text { is difficult for employees. } \\
\mathrm{BD} \text { is difficult to maintain. } \\
\mathrm{BD} \text { is difficult to operate. }\end{array}$ & $\begin{array}{l}\text { Lai et al. } \\
(2018)\end{array}$ \\
\hline Security & $\begin{array}{l}\text { The need to outsource BD creates concerns on data security and } \\
\text { privacy. } \\
\text { The need to outsource BD creates vulnerability in access control of } \\
\text { the business's information asset. } \\
\text { The need to outsource BD creates risks through excessive } \\
\text { dependency towards vendor. } \\
\text { The need to outsource BD complicates the process of implementing } \\
\text { corporate policy in protecting individual privacy and data security. }\end{array}$ & $\begin{array}{l}\text { Salleh \& } \\
\text { Janczewski } \\
(2016)\end{array}$ \\
\hline $\begin{array}{l}\text { Top } \\
\text { Management } \\
\text { Support }\end{array}$ & $\begin{array}{l}\text { Our top management promotes the use of } \mathrm{BD} \text { in the business. } \\
\text { Our top management creates support for } \mathrm{BD} \text { initiatives within the } \\
\text { business. } \\
\text { Our top management promotes } \mathrm{BD} \text { as a strategic prionity within the } \\
\text { business. } \\
\text { Our top Management is interested in the news about } \mathrm{BD} \text { adoption. }\end{array}$ & $\begin{array}{l}\text { Chen et al. } \\
\text { (2015) }\end{array}$ \\
\hline $\begin{array}{l}\text { Organizational } \\
\text { Readiness }\end{array}$ & $\begin{array}{l}\text { Lacking capital/financial resources has prevented my business from } \\
\text { fully exploit BD. } \\
\text { Lacking needed IT infrastructure has prevented my business from } \\
\text { exploiting BD. } \\
\text { Lacking analytics capability prevent the business fully exploit BD. } \\
\text { Lacking skilled resources prevent the business fully exploit BD. }\end{array}$ & $\begin{array}{l}\text { Chen et al. } \\
(2015)\end{array}$ \\
\hline $\begin{array}{l}\text { Competitive } \\
\text { Pressure }\end{array}$ & $\begin{array}{l}\text { Our choice to adopt BD would be strongly influenced by what } \\
\text { competitors in the industry are doing. } \\
\text { Our business is under pressure from competitors to adopt BD. } \\
\text { Our business would adopt BD in response to what competitors are } \\
\text { doing. }\end{array}$ & $\begin{array}{l}\text { Lai et al. } \\
(2018)\end{array}$ \\
\hline $\begin{array}{l}\text { Government } \\
\text { support }\end{array}$ & $\begin{array}{l}\text { The governmental policies encourage our business to adopt new } \\
\text { information technology (e.g., BD). } \\
\text { The government provides incentives for adopting BD in } \\
\text { government procurements and contracts such as offering technical } \\
\text { support, training, and funding for BD adoption. } \\
\text { Standards or laws support adoption of BD technologies. } \\
\text { Adequate legal protection supports BD technology adoption. } \\
\text { There are some business laws to deal with the security and privacy } \\
\text { concerns over the BD technologies. }\end{array}$ & $\begin{array}{l}\text { Hsu et al. } \\
\text { (2014) }\end{array}$ \\
\hline
\end{tabular}

Figure A1. Quantitative questionnaire adopted from previous studies. 


\section{References}

1. Jin, X.; Wah, B.W.; Cheng, X.; Wang, Y. Significance and Challenges of Big Data Research. Big Data Res. 2015, 2, 59-64. [CrossRef]

2. Staegemann, D.; Volk, M.; Lautenschlager, E.; Pohl, M.; Abdallah, M.; Turowski, K. Applying Test Driven Development in the Big Data Domain-Lessons from the Literature. In Proceedings of the 2021 International Conference on Information Technology (ICIT), IEEE, Amman, Jordan, 14-15 July 2021; pp. 511-516. [CrossRef]

3. Gonzales, R.; Wareham, J.; Serida, J. Measuring the impact of data warehouse and business intelligence on en-terprise performance in Peru: A developing country. J. Glob. Inf. Technol. Manag. 2015, 18, 162-187.

4. Wahab, S.N.; Hamzah, M.I.; Sayuti, N.M.; Lee, W.C.; Tan, S.Y. Big data analytics adoption: An empirical study in the Malaysian warehousing sector. Int. J. Logist. Syst. Manag. 2021, 40, 121. [CrossRef]

5. Baig, M.I.; Shuib, L.; Yadegaridehkordi, E. A Model for Decision-Makers' Adoption of Big Data in the Educa-tion Sector. Sustainability 2021, 13, 13995. [CrossRef]

6. Shirdastian, H.; Laroche, M.; Richard, M.-O. Using big data analytics to study brand authenticity sentiments: The case of Starbucks on Twitter. Int. J. Inf. Manag. 2019, 48, 291-307. [CrossRef]

7. Volk, M.; Staegemann, D.; Trifonova, I.; Bosse, S.; Turowski, K. Identifying Similarities of Big Data Projects-A Use Case Driven Approach. IEEE Access 2020, 8, 186599-186619. [CrossRef]

8. International Data Corporation (IDC) (2020). Worldwide Big Data and Analytics Software Forecast, 2021-2026. Available online: https: / / www.reportlinker.com/p06166758/Big-Data-Business-Analytics-Market-Research-Report-by-Analytics-Toolsby-Component-by-Deployment-Mode-by-Application-by-End-User (accessed on 1 December 2021).

9. Verhoef, P.; Kooge, E.; Walk, N. Creating Value with Big Data Analytics: Making Smarter Marketing Decisions; Routledge: London, UK, 2016.

10. Choi, H.S.; Hung, S.-Y.; Peng, C.-Y.; Chen, C. Different Perspectives on BDA Usage by Management Levels. J. Comput. Inf. Syst. 2021, 1-13. [CrossRef]

11. Nam, D.; Lee, J.; Lee, H. Business analytics adoption process: An innovation diffusion perspective. Int. J. Inf. Manag. 2019, 49, 411-423. [CrossRef]

12. Al-Sai, Z.A.; Abdullah, R.; Husin, M.H. Critical Success Factors for Big Data: A Systematic Literature Review. IEEE Access 2020, 8 , 118940-118956. [CrossRef]

13. Almaiah, M.A.; Nasereddin, Y. Factors influencing the adoption of e-government services among Jordanian citizens. Electron. Gov. Int. J. 2020, 16, 236-259.

14. Coleman, S.; Goeb, R.; Manco, G.; Pievatolo, A.; Tort-Martorell, X.; Reis, M.S. How Can SMEs Benefit from Big Data? Challenges and a Path Forward. Qual. Reliab. Eng. Int. 2016, 32, 2151-2164. [CrossRef]

15. Dubey, R.; Gunasekaran, A.; Childe, S.J.; Bryde, D.J.; Giannakis, M.; Foropon, C.; Hazen, B.T. Big data analytics and artificial intelligence pathway to operational performance under the effects of entrepreneurial orientation and environ-mental dynamism: A study of manufacturing organisations. Int. J. Prod. Econ. 2020, 226, 107599. [CrossRef]

16. Almaiah, M.A.; Al-Khasawneh, A.; Althunibat, A.; Khawatreh, S. Mobile Government Adoption Model Based on Combining GAM and UTAUT to Explain Factors According to Adoption of Mobile Government Services. Int. J. Interact. Mob. Technol. (iJIM) 2020, 14, 199-225. [CrossRef]

17. Mikalef, P.; Boura, M.; Lekakos, G.; Krogstie, J. Big data analytics and firm performance: Findings from a mixed-method approach. J. Bus. Res. 2019, 98, 261-276. [CrossRef]

18. Raguseo, E.; Vitari, C. Investments in big data analytics and firm performance: An empirical investigation of direct and mediating effects. Int. J. Prod. Res. 2018, 56, 5206-5221. [CrossRef]

19. Akter, S.; Fosso Wamba, S.; Dewan, S. Why PLS-SEM is suitable for complex modelling? An empirical illustra-tion in big data analytics quality. Prod. Plan. Control. 2017, 28, 1011-1021. [CrossRef]

20. Ghasemaghaei, M. Does data analytics use improve firm decision making quality? The role of knowledge sharing and data analytics competency. Decis. Support Syst. 2019, 120, 14-24. [CrossRef]

21. O'Connor, C.; Kelly, S. Facilitating knowledge management through filtered big data: SME competitiveness in an agri-food sector. J. Knowl. Manag. 2017, 21, 156-179. [CrossRef]

22. Nam, D.-W.; Kang, D.-W.; Kim, S. Process of big data analysis adoption: Defining big data as a new IS innova-tion and examining factors affecting the process. In Proceedings of the 2015 48th Hawaii International Conference on System Sciences, Kauai, HI, USA, 5-8 January 2015; pp. 4792-4801.

23. Munawar, H.S.; Qayyum, S.; Ullah, F.; Sepasgozar, S. Big Data and Its Applications in Smart Real Estate and the Disaster Management Life Cycle: A Systematic Analysis. Big Data Cogn. Comput. 2020, 4, 4. [CrossRef]

24. Chandra, S.; Kumar, K.N. Exploring factors influencing organizational adoption of augmented reality in e-commerce: Empirical analysis using technology-organization-environment model. J. Electron. Commer. Res. 2018, 19, 237-265.

25. Maroufkhani, P.; Wagner, R.; Wan Ismail, W.K.; Baroto, M.B.; Nourani, M. Big data analytics and firm per-formance: A systematic review. Information 2019, 10, 226. [CrossRef]

26. Althunibat, A.; Binsawad, M.; Almaiah, M.A.; Almomani, O.; Alsaaidah, A.; Al-Rahmi, W.; Seliaman, M.E. Sustainable Applications of Smart-Government Services: A Model to Understand Smart-Government Adoption. Sustainability 2021, $13,3028$. [CrossRef] 
27. Lutfi, A.; Al-Okaily, M.; Alsyouf, A.; Alsaad, A.; Taamneh, A. The Impact of AIS Usage on AIS Effectiveness Among Jordanian SMEs: A Multi-group Analysis of the Role of Firm Size. Glob. Bus. Rev. 2020, 21, 1-19. [CrossRef]

28. Alharbi, F.; Atkins, A.; Stanier, C. Understanding the determinants of Cloud Computing adoption in Saudi healthcare organisations. Complex Intell. Syst. 2016, 2, 155-171. [CrossRef]

29. Sun, S.; Hall, D.J.; Cegielski, C.G. Organizational intention to adopt big data in the B2B context: An integrat-ed view. Ind. Mark. Manag. 2020, 86, 109-121. [CrossRef]

30. Gangwar, H.; Date, H.; Raoot, A. Review on IT adoption: Insights from recent technologies. J. Enterp. Inf. Manag. 2014, 27, 488-502. [CrossRef]

31. Lutfi, A.A.; Idris, K.M.; Mohamad, R. AIS usage factors and impact among Jordanian SMEs: The moderating effect of environmental uncertainty. J. Adv. Res. Bus. Manag. Stud. 2017, 6, 24-38.

32. Yoon, T.E.; George, J.F. Why aren't organizations adopting virtual worlds? Comput. Hum. Behav. 2013, 29, 772-790. [CrossRef]

33. Arias-Aranda, D.; Bustinza, O.F.; Barrales-Molina, V. Operations flexibility and outsourcing benefits: An em-pirical study in service firms. Serv. Ind. J. 2011, 31, 1849-1870. [CrossRef]

34. Frizzo-Barker, J.; Chow-White, P.A.; Charters, A.; Ha, D. Genomic big data and privacy: Challenges and op-portunities for precision medicine. Comput. Supported Coop. Work. 2016, 25, 115-136. [CrossRef]

35. Al-Hujran, O.; Wadi, R.; Dahbour, R.; Al-Doughmi, M.; Al-Debei, M.M. Big Data: Opportunities and Chal-lenges. In Proceedings of the Fifth International Conference on Business Intelligence and Technology, Nice, France, 22-27 March 2015 ; pp. 73-79.

36. Hashem IA, T.; Chang, V.; Anuar, N.B.; Adewole, K.; Yaqoob, I.; Gani, A.; Ahmed, E.; Chiroma, H. The role of big data in smart city. Int. J. Inf. Manag. 2016, 36, 748-758. [CrossRef]

37. Agrawal, R.; Kadadi, A.; Dai, X.; Andres, F. Challenges and opportunities with big data visualization. In Proceedings of the 7th International Conference on Management of Computational and Collective intelligence in Digital EcoSystems, Caraguatatuba, Brazil, 25 October 2015; pp. 169-173.

38. Sun, S.; Cegielski, C.G.; Jia, L.; Hall, D.J. Understanding the Factors Affecting the Organizational Adoption of Big Data. J. Comput. Inf. Syst. 2016, 58, 193-203. [CrossRef]

39. Surbakti, F.P.S.; Wang, W.; Indulska, M.; Sadiq, S. Factors influencing effective use of big data: A research framework. Inf. Manag. 2019, 57, 103146. [CrossRef]

40. Russom, P. Big data analytics. TDWI best practices report, fourth quarter. Int. J. Sustain. Dev. Comput. Sci. 2011, 19, 1-34.

41. Shukla, A.K.; Yadav, M.; Kumar, S.; Muhuri, P.K. Veracity handling and instance reduction in big data using interval type-2 fuzzy sets. Eng. Appl. Artif. Intell. 2019, 88, 103315. [CrossRef]

42. Ajimoko, O.J. Considerations for the Adoption of Cloud-based Big Data Analytics in Small Business Enterprises. Electron. J. Inf. Syst. Eval. 2018, 21, 63-79.

43. Mangla, S.K.; Raut, R.; Narwane, V.S.; Zhang, Z.; Priyadarshinee, P. Mediating effect of big data analytics on project performance of small and medium enterprises. J. Enterp. Inf. Manag. 2020, 34, 168-198. [CrossRef]

44. Nasrollahi, M.; Ramezani, J.; Sadraei, M. The Impact of Big Data Adoption on SMEs' Performance. Big Data Cogn. Comput. 2021, 5, 68. [CrossRef]

45. Maroufkhani, P.; Tseng, M.L.; Iranmanesh, M.; Ismail, W.K.; Khalid, H. Big data analytics adoption: Determinants and performances among small to medium-sized enterprises. Int. J. Inf. Manag. 2020, 54, 102190. [CrossRef]

46. Park, J.-H.; Kim, M.-K.; Paik, J.-H. The Factors of Technology, Organization and Environment Influencing the Adoption and Usage of Big Data in Korean Firms. In Proceedings of the 26th European Regional Conference of the International Telecommunications Society (ITS): "What Next for European Telecommunications?", Madrid, Spain, 24-27 June 2015.

47. Skafi, M.; Yunis, M.M.; Zekri, A. Factors Influencing SMEs' Adoption of Cloud Computing Services in Lebanon: An Empirical Analysis Using TOE and Contextual Theory. IEEE Access 2020, 8, 79169-79181. [CrossRef]

48. Loh, C.-H.; Teoh, A.-P. The Adoption of Big Data Analytics Among Manufacturing Small and Medium Enterprises During Covid-19 Crisis in Malaysia. In Proceedings of the Ninth International Conference on Entrepreneurship and Business Management; Atlantis Press: Paris, France, 2021; pp. 95-100. [CrossRef]

49. Parson, G.K. Factors Affecting Information Technology Professionals' Decisions to Adopt Big Data Analytics Among Small-and Medium-Sized Enterprises: A Quantitative Study. Ph.D. Thesis, Capella University, Minneapolis, MN, USA, 2021.

50. Mikalef, P.; Krogstie, J.; Pappas, I.O.; Pavlou, P. Exploring the relationship between big data analytics capability and competi-tive performance: The mediating roles of dynamic and operational capabilities. Inf. Manag. 2020, 57, 103169. [CrossRef]

51. Oliveira, T.; Martins, R.; Sarker, S.; Thomas, M.; Popovič, A. Understanding SaaS adoption: The moderating impact of the environment context. Int. J. Inf. Manag. 2019, 49, 1-12. [CrossRef]

52. Hameed, M.A.; Counsell, S.; Swift, S. A conceptual model for the process of IT innovation adoption in organ-izations. J. Eng. Technol. Manag. 2012, 29, 358-390. [CrossRef]

53. Kapoor, K.K.; Dwivedi, Y.K.; Williams, M.D. Examining the role of three sets of innovation attributes for de-termining adoption of the interbank mobile payment service. Inf. Syst. Front. 2015, 17, 1039-1056. [CrossRef]

54. Rogers, E.M. Diffusion of Innovations, 5th ed.; Free Press: New York, NY, USA, 2003.

55. Lutfi, A. Understanding Cloud Based Enterprise Resource Planning Adoption among SMEs in Jordan. J. Theor. Appl. Inf. Technol. 2021, 99, 5944-5953. 
56. Lutfi, A.; Al-Okaily, M.; Alshirah, M.H.; Alshira'h, A.F.; Abutaber, T.A.; Almarashdah, M.A. Digital Finan-cial Inclusion Sustainability in Jordanian Context. Sustainability 2021, 13, 6312. [CrossRef]

57. Oliveira, T.; Thomas, M.; Espadanal, M. Assessing the determinants of cloud computing adoption: An analysis of the manufacturing and services sectors. Inf. Manag. 2014, 51, 497-510. [CrossRef]

58. Lutfi, A.A.; Idris, K.M.; Mohamad, R. The influence of technological, organizational and environmental fac-tors on accounting information system usage among Jordanian small and medium-sized enterprises. Int. J. Econ. Financ. Issues 2016, 6, $240-248$.

59. Kandil, A.M.N.A.; Ragheb, M.A.; Ragab, A.A.; Farouk, M. Examining the effect of TOE model on cloud computing adoption in Egypt. Bus. Manag. Rev. 2018, 9, 113-123.

60. Asiaei, A.; Rahim, N.Z.A. A multifaceted framework for adoption of cloud computing in Malaysian SMEs. J. Sci. Technol. Policy Manag. 2019, 10, 708-750. [CrossRef]

61. Kung, L.; Cegielski, C.G.; Kung, H.J. An integrated environmental perspective on software as a service adop-tion in manufacturing and retail firms. J. Inf. Technol. 2015, 30, 352-363. [CrossRef]

62. Al Amri, M.; Almaiah, M.A. Sustainability Model for Predicting Smart Education Technology Adoption Based on Student Perspectives. Int. J. Adv. Soft Comput. Its Appl. 2021, 13, 2.

63. Gangwar, H. Understanding the determinants of big data adoption in India: An analysis of the manufacturing and services sectors. Inf. Resour. Manag. J. 2018, 31, 22. [CrossRef]

64. Lai, Y.; Sun, H.; Ren, J. Understanding the determinants of big data analytics (BDA) adoption in logistics and supply chain management: An empirical investigation. Int. J. Logist. Manag. 2018, 29, 676-703. [CrossRef]

65. Awa, H.O.; Ukoha, O.; Igwe, S.R. Revisiting technology-organization-environment (T-O-E) theory for enriched applicability. Bottom Line 2017, 30, 2-22. [CrossRef]

66. Verma, S.; Bhattacharyya, S.S. Perceived strategic value-based adoption of Big Data Analytics in emerging economy: A qualitative approach for Indian firms. J. Enterp. Inf. Manag. 2017, 30, 354-382. [CrossRef]

67. Alshamaila, Y.; Papagiannidis, S.; Li, F. Cloud computing adoption by SMEs in the north east of England: A multi-perspective framework. J. Enterp. Inf. Manag. 2013, 26, 250-275. [CrossRef]

68. Ghasemaghaei, M. The role of positive and negative valence factors on the impact of bigness of data on big data analytics usage. Int. J. Inf. Manag. 2018, 50, 395-404. [CrossRef]

69. Raut, R.D.; Priyadarshinee, P.; Gardas, B.B.; Jha, M.K. Analyzing the factors influencing cloud computing adoption using three stage hybrid SEM-ANN-ISM (SEANIS) approach. Technol. Forecast. Soc. Chang. 2018, 134, 98-123. [CrossRef]

70. Priyadarshinee, P.; Raut, R.D.; Jha, M.K.; Kamble, S.S. A cloud computing adoption in Indian SMEs: Scale development and validation approach. J. High Technol. Manag. Res. 2017, 28, 221-245. [CrossRef]

71. Sanders, N.R. Pattern of information technology use: The impact on buyer-suppler coordination and perfor-mance. J. Oper. Manag. 2008, 26, 349-367. [CrossRef]

72. Jahanshahi, A.A.; Brem, A. Sustainability in SMEs: Top Management Teams Behavioral Integration as Source of Innovativeness. Sustainability 2017, 9, 1899. [CrossRef]

73. Cruz-Jesus, F.; Pinheiro, A.; Oliveira, T. Understanding CRM adoption stages: Empirical analysis building on the TOE framework. Comput. Ind. 2019, 109, 1-13. [CrossRef]

74. Ramdani, B.; Kawalek, P. Exploring SMEs adoption of broadband in the northwest of England. In Handbook of Research on Global Diffusion of Broadband Data Transmission; IGI Global: Hershey, PA, USA, 2008; pp. 504-523.

75. Xu, W.; Ou, P.; Fan, W. Antecedents of ERP assimilation and its impact on ERP value: A TOE-based model and empirical test. Inf. Syst. Front. 2015, 19, 13-30. [CrossRef]

76. Grandon, E.; Pearson, J. Electronic commerce adoption: An empirical study of small and medium US businesses. Inf. Manag. 2004, 42, 197-216. [CrossRef]

77. Chen, D.Q.; Preston, D.S.; Swink, M. How the Use of Big Data Analytics Affects Value Creation in Supply Chain Management. J. Manag. Inf. Syst. 2015, 32, 4-39. [CrossRef]

78. Lautenbach, P.; Johnston, K.; Adeniran-Ogundipe, T. Factors influencing business intelligence and analytics usage extent in South African organisations. South Afr. J. Bus. Manag. 2017, 48, 23-33. [CrossRef]

79. Tornatzky, L.G.; Fleischer, M.; Chakrabarti, A.K. Processes of Technological Innovation; Lexington Books: Lanham, MD, USA, 1990.

80. Ifinedo, P. Factors influencing e-government maturity in transition economies and developing countries: A longi-tudinal perspective. ACM SIGMIS Database: Adv. Inf. Syst. 2012, 42, 98-116. [CrossRef]

81. Hameed, M.A.; Counsell, S. Assessing the influence of Environmental and CEO Characteristics for Adoption of Information Technology in Organizations. J. Technol. Manag. Innov. 2012, 7, 64-84. [CrossRef]

82. Dwivedi, M.; Laddha, N.C.; Arora, P.; Marfatia, Y.S.; Begum, R. Decreased regulatory T-cells and CD 4+/CD 8+ ratio correlate with disease onset and progression in patients with generalized vitiligo. Pigment. Cell Melanoma Res. 2013, 26, 586-591. [CrossRef]

83. Hair, J.F.; Risher, J.J.; Sarstedt, M.; Ringle, C.M. When to use and how to report the results of PLS-SEM. Eur. Bus. Rev. 2019, 31, 2-24. [CrossRef]

84. Agrawal, K.P. Investigating the determinants of Big Data Analytics (BDA) adoption in emerging economies. Acad. Manag. Proc. 2015, 2015, 11290. [CrossRef] 
85. Salleh, K.A.; Janczewski, L. Adoption of Big Data Solutions: A study on its security determinants using Sec-TOE Framework. In Proceedings of the International Conference on Information Resources Management (CONFIRM), Cape Town, South Africa, 18-20 May 2016.

86. Hsu, P.F.; Ray, S.; Li-Hsieh, Y.Y. Examining cloud computing adoption intention, pricing mechanism, and deployment model. Int. J. Inf. Manag. 2014, 34, 474-488. [CrossRef]

87. Jordan Chamber of Industry [JCI]. 2020. Available online: http://www.aci.org.jo/development/en/ (accessed on 1 December 2021).

88. King, W.R.; He, J. External validity in IS survey research. Commun. Assoc. Inf. Syst. 2005, 16, 45. [CrossRef]

89. Alqudah, H.; Amran, N.; Hassan, H. Factors affecting the internal auditors' effectiveness in the Jordanian pub-lic sector: The moderating effect of task complexity. EuroMed. J. Bus. 2019, 14, 251-273. [CrossRef]

90. Al-Okaily, M.; Lutfi, A.; Alsaad, A.; Taamneh, A.; Alsyouf, A. The Determinants of Digital Payment Systems' Acceptance under Cultural Orientation Differences: The Case of Uncertainty Avoidance. Technol. Soc. 2020, 63, 101367. [CrossRef]

91. Alshira'H, A.; Alsqour, M.; Lutfi, A.; Alsyouf, A.; Alshirah, M. A Socio-Economic Model of Sales Tax Compliance. Economies 2020, 8, 88. [CrossRef]

92. Alsyouf, A.; Masa'Deh, R.; Albugami, M.; Al-Bsheish, M.; Lutfi, A.; Alsubahi, N. Risk of Fear and Anxiety in Utilising Health App Surveillance Due to COVID-19: Gender Differences Analysis. Risks 2021, 9, 179. [CrossRef]

93. Fornell, C.; Larcker, D.F. Structural equation models with unobservable variables and measurement error: Al-gebra and statistics. J. Mark. Res. 1981, 18, 382-388. [CrossRef]

94. Chin, W.W. How to write up and report PLS analyses. In Handbook of Partial Least Squares; Springer: Berlin, Germany, 2010; pp. 655-690.

95. Garg, A.; Choeu, T. The Adoption of Electronic Commerce by SMEs in Pretoria East. Electron. J. Inf. Syst. Dev. Ctries 2015, 68, 1-23. [CrossRef]

96. Park, J.-H.; Kim, Y.B. Factors Activating Big Data Adoption by Korean Firms. J. Comput. Inf. Syst. 2019, 61, 285-293. [CrossRef]

97. Choudhury, V.; Sabherwal, R. Portfolios of Control in Outsourced Software Development Projects. Inf. Syst. Res. 2003, 14, 291-314. [CrossRef]

98. Bush, A.A.; Tiwana, A.; Tsuji, H. An empirical investigation of the drivers of software outsourcing decisions in Japanese organizations. Inf. Softw. Technol. 2008, 50, 499-510. [CrossRef]

99. Kim, A.J.; Ko, E. Impacts of luxury fashion brand's social media marketing on customer relationship and pur-chase intention. J. Glob. Fash. Mark. 2010, 1, 164-171. [CrossRef]

100. Scupola, A. SMEs' e-commerce adoption: Perspectives from Denmark and Australia. J. Enterp. Inf. Manag. 2009, 22, 152-166. [CrossRef]

101. Salwani, M.I.; Marthandan, G.; Norzaidi, M.D.; Chong, S.C. E-commerce usage and business performance in the Malaysian tourism sector: Empirical analysis. Inf. Manag. Comput. Secur. 2009, 17, 166-185. [CrossRef]

102. Zhu, K.; Kraemer, K.L. Post-Adoption Variations in Usage and Value of E-Business by Organizations: Cross-Country Evidence from the Retail Industry. Inf. Syst. Res. 2005, 16, 61-84. [CrossRef]

103. Chwelos, P.; Benbasat, I.; Dexter, A.S. Research Report: Empirical Test of an EDI Adoption Model. Inf. Syst. Res. 2001, 12, 304-321. [CrossRef]

104. Alshirah, M.H.; Lutfi, A.; Alshira'H, A.F.; Saad, M.; Ibrahim, N.M.E.S.; Mohammed, F.M. Influences of the environmental factors on the intention to adopt cloud based accounting information system among SMEs in Jordan. Accounting 2021, 7, 645-654. [CrossRef]

105. Lutfi, A. Investigating the moderating effect of Environment Uncertainty on the relationship between institution-al factors and ERP adoption among Jordanian SMEs. J. Open Innov.: Technol. Mark. Complex. 2020, 6, 91. [CrossRef] 